\section{Stimulatory Role of Glycated Fetal Bovine Serum Along with Iron on In Vitro Production of Insulin by Differentiated Mouse Embryonic Stem Cells}

\author{
Ikuo Nishigaki, ${ }^{*}, a$ \\ Gowri Rangasamy Gunassekaran, ${ }^{a}$ \\ Panjan Nagappan Venkatesan, ${ }^{a}$ \\ Mandupal Chaco Sabu, ${ }^{a}$ Sabu Priya, ${ }^{a}$ \\ Peramaiyan Rajendran, ${ }^{a}$ \\ Dhanapal Sakthisekaran, ${ }^{b}$ and \\ Yutaka Nishigaki ${ }^{a}$
}

${ }^{a}$ NPO International Laboratory of Biochemistry, 1-166 Uchide, Nakagawa-ku, Nagoya 454-0926, Japan and ${ }^{b}$ Department of Medical Biochemistry, University of Madras, Taramani Campus, Chennai 600 113, India

(Received March 25, 2011; Accepted May 13, 2011; Published online May 13, 2011)

Mouse embryonic stem cells were caused to differentiate into insulin-producing cells by 2 methods: Stem cells were cultured with or without feeder cells. In both cases, after confirmation of their differentiation into the insulin producing cells, the effects of the addition of $10 \mu \mathrm{l}$ of $50 \mathrm{mM}$ glucose, $10 \mu \mathrm{l}$ of glycated fetal bovine serum (GFBS) and $10 \mu \mathrm{l}$ of GFBS + $20 \mathrm{mM}$ iron on the differentiated stem cells were examined. The addition of GFBS or GFBS + iron to the cultures with or without the feeder cells caused them to produce a significantly higher amount of insulin than did the addition of glucose. However, this enhancement by GFBS or GFBS + iron stopped after $12 \mathrm{hr}$ of addition; and the culture medium was turned yellow after $15 \mathrm{hr}$ and at that time the cells died, which may be due to the cytotoxicity of GFBS or GFBS + iron.

Key words — embryonic stem cell, insulin-producing cell, diabetes mellitus, advanced glycation end product, glycated fetal bovine serum, iron-chelate

\footnotetext{
*To whom correspondence should be addressed: NPO International Laboratory of Biochemistry, 1-166 Uchide, Nakagawaku, Nagoya 454-0926, Japan. Tel.: +81-52-361-1601; Fax: +81-52-353-4406; E-mail: nishigaki@se.starcat.ne.jp
}

\section{INTRODUCTION}

Ever since methods for the measurement of lipid peroxide in serum were first published ${ }^{1,2)}$ many reports on the cytotoxicity of glycated fetal bovine serum (GFBS) or GFBS + iron, especially associated with atherosclerosis ${ }^{3,4)}$ diabetes $^{5,6)}$ and cancer $^{7)}$ have been reported. Type 1 diabetes occurs as a result of high blood glucose levels in an insulin deficient condition. Several approaches have been used to reverse the disease process for Type 1 diabetes, including whole organ pancreas transplants and islet transplants. ${ }^{8)}$ One article described the toxic effects of advanced glycation end-products (AGEs) on insulin-secreting cells. Chronically high intracellular oxidative stress, due to the accumulation of AGEs, affects the insulin secretion machinery. ${ }^{9)}$ As for as the effect of AGEs on the differentiation of stem cells is concerned, the AGE attenuate human mesenchymal stem cells and prevent cognate differentiation into adipose tissue, cartilage, and bone. ${ }^{10)}$ Previously we have reported that glycated protein/iron chelate induced toxicity in human umbilical vein endothelial cells in vitro. ${ }^{11)}$ During hyperglycemia, body proteins undergo increased glycation where in glucose reacts non-enzymatically with protein amino groups to form a labile Schiff base that rearranges to form a stable Amadori product. This Amadori product undergoes further reactions involving dicarbonyl intermediates such as 3deoxyglucosone and ethyl-glyoxal to form AGEs. The level of glycoproteins is known to increase in diabetic patients, and the fructosamine value (FV) of serum is regarded as an index of blood glucose level. Diabetes mellitus is a chronic metabolic syndrome characterized by increased levels of blood glucose, referred as hyperglycemia. Type 1 diabetes results from the body's failure to produce insulin, which presently requires insulin injection as treatment: Type 2 diabetes results from insulin resistance, a condition in which cells fail to use insulin properly, sometimes combined with an absolute insulin deficiency. For Type 1 diabetes, especially insulin injection therapy is the principal current treatment; and patients suffer from various complications generated by insufficient control of blood glucose levels over a long period.

Embryonic stem (ES) cells have been proposed to be a powerful tool for the treatment of diabetes mellitus. ES cells are pluripotent cells derived from 
the inner cell mass of the mammalian blastocyst. ES cells are uniquely endowed with the capability for unlimited self renewal and multi-lineage differentiation. These characteristics make ES cells a potential source of insulin-producing cells for transplantation therapy. The cytotoxicity of AGEs stimulates the generation of reactive oxygen species, but does not arrest the proliferation of the INS-1 cell line (a pancreatic beta cell line) or islets cells in primary culture, both of which possess a receptor for AGE (RAGE); and the expression of this receptor increases after AGE treatment. ${ }^{12)}$ According to the results of a literature survey, we could find no study on the effect of GFBS or glycated proteiniron chelate on stem cells differentiated into insulinproducing like cells. Therefore, we studied this issue and found that GFBS had a stimulatory effect on these differentiated cells. However, the mechanism remains unclear. Our findings suggest that the toxicity of GFBS needs to be studied further at the molecular level.

\section{MATERIALS AND METHODS}

Stem Cell Culture and Differentiation — The embryonic stem cell line used for this project was CMTI-1 (Millipore Co., Billerica, MA, U.S.A.). Briefly ESCs were maintained on precoated gelatin T flasks (Nunc., Roskilde, Denmark) with or without mitotically inactivated feeder layer of primary culture of mouse embryonic fibroblast (PMEF-P3 cells; Millipore Co.) in ESC medium containing knockout Dulbecco's modified Eagle medium (KO-DMEM; Invitrogen, Paisley, U.K.), supplemented with $100 \mathrm{U} / \mathrm{ml}$ penicillin, $100 \mu \mathrm{g} / \mathrm{ml}$ streptomycin, $100 \mu \mathrm{M} \beta$-mercaptoethanol, $2 \mathrm{mM} \mathrm{L-}$ glutamine, $1 \%$ non-essential amino acids, $15 \%$ FBS, and $1000 \mathrm{U} / \mathrm{ml}$ leukemia inhibitory factor (LIF; Chemicon, Temecula, CA, U.S.A.). Cultures were grown in $5 \% \mathrm{CO}_{2}$ at $37^{\circ} \mathrm{C}$ and were checked frequently and the medium was changed every two days. All chemicals used were of analytical grade, and water was purified by using a Millipore Milli Q system (Millipore Co.).

Glycation of FBS — For the glycation of FBS, $100 \mathrm{ml}$ of FBS was incubated with $50 \mathrm{mM}$ glucose at $37^{\circ} \mathrm{C}$ for 50 days under sterile conditions. After the incubation, the mixture was dialyzed against $67 \mathrm{mM}$ phosphate buffer $(\mathrm{pH} 7.4)$ at $4^{\circ} \mathrm{C}$. The dialysate was used as GFBS after having been concentrated by using an Aquacide II (Calbiochem-
Novabiochem Corp., La Jolla, CA, U.S.A.). Pentosidine content was evaluated as a measure of glycations. The concentration of pentosidine in GFBS was $0.03 \mu \mathrm{g} / \mathrm{ml}$ in experimental media. The extent of glycation of GFBS was assayed with a commercial kit (Nippon Roche, Tokyo, Japan) and expressed as the FV. The FV of the prepared GFBS was $12 \mathrm{mM}$, whereas that of the original FBS was $0.16 \mathrm{mM}$.

Two Different Methods Used to Differentiate Mouse ES Cells into Insulin-producing Cells

Method 1. Stem Cells Were Differentiated with Feeder Cells: Stage 1: mouse ES cells were cultured on a gelatin-coated culture surface with a feeder layer in ESC medium for 4 days to maintain the cells in the undifferentiated state.

Stage 2: to induce differentiation and to select Nestin positive cells the medium was exchanged to DMEM/F12 medium (GIBCO 10565, Carlsbad, CA, U.S.A.) supplemented with $50 \mu \mathrm{l}$ of ITS (Sigma-Aldrich, 11884, St. Louis, MO, U.S.A.) and $25 \mu \mathrm{l}$ of fibronectin (Sigma F0635) per flask containing $5 \mathrm{ml}$ of culture medium. The culture medium was renewed every two days. Nestin positive cells were selected after cultivation for further 7 days.

Stage 3: the stem cells were then sequentially incubated in DMEM/F12 medium along with Activin B (10 ng/ml; R\&D system Inc., Minneapolis, MN, U.S.A.) for 4 days; the medium was changed every two days. The differentiation of insulin secreting cells was induced by DMEM/F12 with $10 \mathrm{mM}$ Nicotinamide (Sigma N5535) for 7 days. The medium was changed every two days. The differentiation of stem cells into insulin-producing cells was determined by an insulin release test. Insulin release was induced in the differentiated cells by addition of glucose.

Method 2. Stem Cells were Differentiated without Feeder Cells: Stage 1: mouse ES cells were cultured on a gelatin-coated culture surface with a feeder layer in ESC medium for 4 days to maintain the cells in the undifferentiated state.

Stage 2. Stem cell separation on Histopaque density gradient: ES cells grown on the feeder cell layers were collected by centrifugation after trypsin treatment, resuspended in $4 \mathrm{ml}$ of ES medium, and subjected to Histopaque density-gradient separation $^{13)}$ (Fig. 1).

Stage 3: separated ES cells were transferred to flasks coated with poly-L-ornithine and laminin peptide. To select nestin-positive cells, ES cells 
were maintained for 7 days in culture flasks containing serum-free medium supplemented with ITS solution having final concentrations of $10 \mathrm{mg} / \mathrm{l}$ insulin, $56 \mathrm{mg} / \mathrm{l}$ transferrin, $6.7 \mathrm{mg} / \mathrm{l}$ selenium, and $5 \mathrm{mg} / \mathrm{l}$ fibronectin. Nestin-positive cells were cultured for 4 days in the presence of Activin B $(10 \mathrm{ng} / \mathrm{ml}$, GIBCO/BRL) in serum-free medium to expand the pancreatic progenitor cells. In order to induce the differentiation of the cells into insulin-producing cells, $10 \mathrm{mM}$ nicotinamide (Sigma) was added to the cultures. The differentiation of stem cells into insulin-producing cells was determined by stimulating the cells for insulin production using glucose and by subjecting the cells for an insulin release test. As our interest is strongly set on the effect of AGEs and iron on stem cell, our data was collected only using stem cells differentiated by method 2 .

Measurement of Insulin — Insulin was measured using architect insulin assay system from $\mathrm{Ab}$ bott. This assay is a chemiluminescent microparticle immunoassay (CMIA) for the quantitative determination of insulin.

Effect of GFBS and GFBS + Iron: The cells differentiated by method 1 and method 2 were grouped as follow. Group 1: control (cells in $5 \mathrm{ml}$ of DMEM/F12 medium). Group 2: cells in $5 \mathrm{ml}$ of DMEM/F12 medium treated with $10 \mu \mathrm{l}$ GFBS. Group 3: cells in $5 \mathrm{ml}$ of DMEM/F12 medium treated with $10 \mu \mathrm{l}$ GFBS and $20 \mathrm{mM}$ iron. Group 4: cells in $5 \mathrm{ml}$ of DMEM/F12 medium treated with $10 \mu l$ glucose.

The cells differentiated by method 1 were subjected to insulin release test after $10 \mathrm{hr}$ of treatment while the cells differentiated by method 2 were subject to insulin release test at time intervals of 5, 10

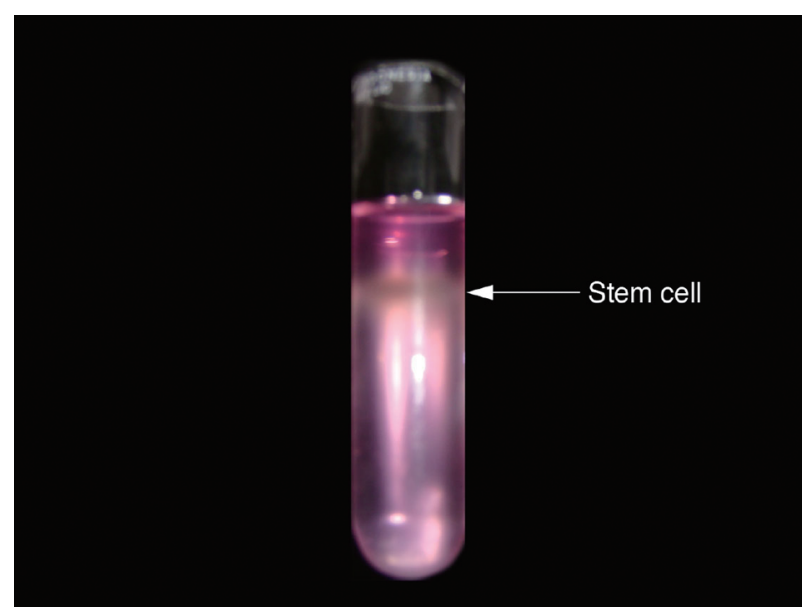

Fig. 1. Separation of ES Cells and $12 \mathrm{hr}$ respectively. The insulin release test was considered to exhibit the effect of GFBS and GFBS + iron on differentiated insulin producing cells.

Measurement of Protein — The differentiated ES cells were lysed using total protein cell lysis buffer (Amresco-M329, Solon, OH, U.S.A.) and the total cell protein was measured using a DC Protein Assay Kit from Bio-Rad (Bio-Rad, Hercules, CA, U.S.A.). The method is a colorimetric assay for determining protein concentrations following detergent solubilization. The reaction is similar to the well-documented Lowry's method. ${ }^{14)}$

\section{RESULTS}

\section{Determination of the Effect of GFBS and Iron on Differentiated Mouse ES Cells into Insulin- producing Cells}

Cells differentiated at the end of method 1 were examined for insulin release potential after $10 \mathrm{hr}$ of incubation with GFBS, GFBS + iron and glucose, respectively. The insulin production was significantly increased in group 2 and group 3 when compare with group 1 and group 4 (Fig. 2).

Cells differentiated at the end of method 2 were examined for insulin release potential at time intervals of 5,10 , and $12 \mathrm{hr}$ of incubation with GFBS, GFBS + iron and glucose, respectively. The insulin production was significantly increased in group 2 and group 3 when compare with group 1 and group 4 (Fig. 3).

But after $15 \mathrm{hr}$ incubation with GFBS or GFBS

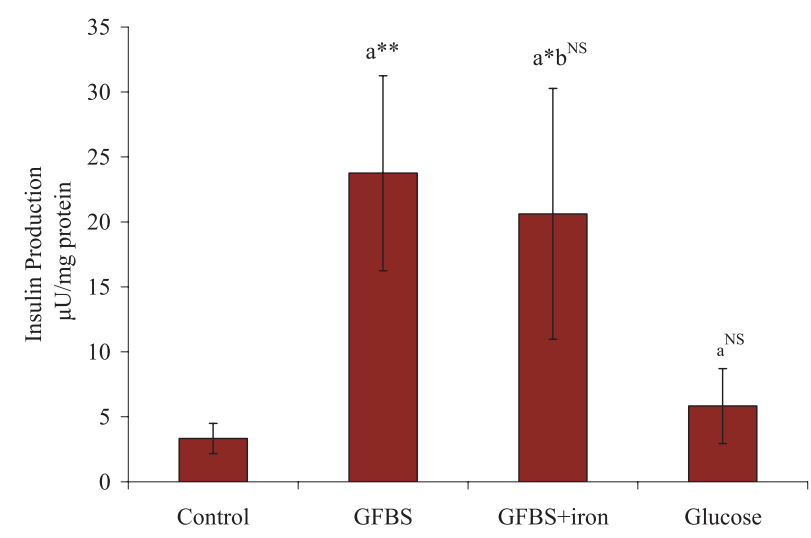

Fig. 2. Effect of GFBS, GFBS + Iron, and Glucose on Insulinproducing Differentiated Stem Cells

Stem cells were cultured with feeder cells. Values shown are the mean \pm S.D., $n=6$ ). Units: $\mu \mathrm{U} / \mathrm{mg}$ protein. a: as compared with group I (control), b: as compared with group II (GFBS). Statistical significance: ${ }^{*} p<0.01,{ }^{* *} p<0.001$, NS: not significant. 


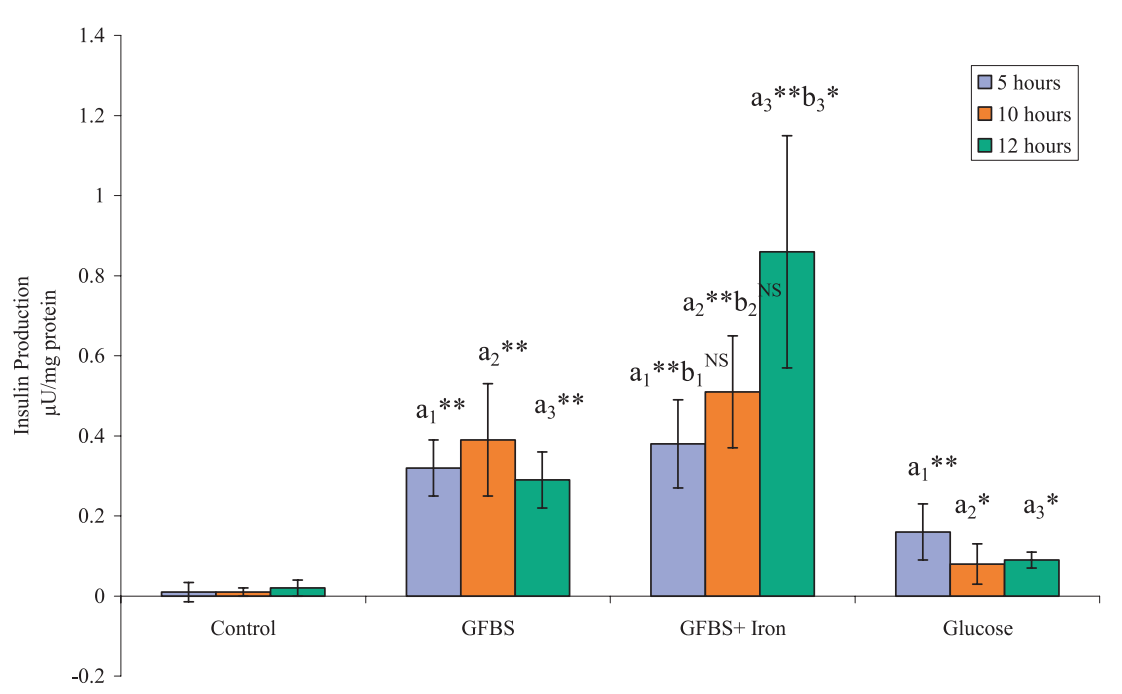

Fig. 3. Effect of GFBS, GFBS + Iron and Glucose on Insulin-producing Differentiated Stem Cells after 5, 10 and $12 \mathrm{hr}$ Incubation (Time Course)

Stem cells were cultured without feeder cells. Values shown are the mean \pm S.D., $n=6$. Units: $\mu \mathrm{U} / \mathrm{mg}$ protein. $\mathrm{a}_{1}, \mathrm{a}_{2}, \mathrm{a}_{3}$ : as compared with group I (control), $\mathrm{b}_{1}, \mathrm{~b}_{2}, \mathrm{~b}_{3}$ : as compared with group II (GFBS). Statistical significance: ${ }^{*} p<0.01,{ }^{* *} p<0.001$, NS: not significant.

+ iron, the colour of the medium gradually changed to yellow which could be due to the cytotoxicity of GFBS or GFBS + iron on the stem cells.

\section{DISCUSSION}

Diabetes mellitus is a chronic incurable condition due to insulin deficiency, and it affects $10 \%$ of the population worldwide. The number of diabetic people is expected to rise from the present estimate of 150 million to 230 million by $2025 .^{15)}$ ES cells provide an excellent in vitro system for the generation of organ-specific cell types and are an attractive source of material for the development of novel cell-based therapeutics. Recent studies have shown that mouse ES cells can differentiate into insulin producing cells and form structures that resemble those of pancreatic islets by varying the culture conditions. ${ }^{16,17)}$ However, it was later shown that the observed insulin immunoreactivity was due to insulin uptake from the medium or due to contamination by other types of insulin-positive cells (e.g., neuronal cells) rather than endogenous biosynthesis of insulin. ${ }^{18,19)}$

Glucose and Amadori products can undergo autoxidation in the presence of transition metals to generate free radicals. Similarly, Amadori products undergo metal-catalyzed oxidation (glycoxidation), generating reactive dicarbonyl compounds capable of forming AGEs and free radicals. ${ }^{2)}$ The levels of
AGEs are increased in the serum of patients with diabetes. AGEs have been linked to retinopathy, nephropathy, and neuropathy, as well as to large vessel disease. The mechanisms leading to microand macro-angiopathy are thought to occur by an interaction of AGE with a receptor (known as RAGE) expressed on the cell-surface membrane of vascular endothelial cells. ${ }^{20)}$ The present study demonstrated that ES cells could differentiate into functional pancreatic beta-like cells and that after the administration of GFBS alone or with iron showed a time-dependent increase in insulin secretion into the medium. Earlier Luciano ${ }^{9)}$ reported that, glycated fetal calf serum gradually decreases the amount of insulin secretion, inhibits the proliferation, and reduces the viability of cells of beta cell line HIT-T15 after 5 days exposure to the glycated serum.

AGEs inhibit the proliferation of mesenchymal stem cells, cause apoptosis and prevent their cognate differentiation into adipose tissue, cartilage, and bone with partial involvement of the AGERAGE interaction. ${ }^{10)}$ On the other hand, AGEs have the ability to promote proliferation of cells under specific conditions. In bovine retinal endothelial cells, AGEs enhance reactive oxygen species (ROS) generation, protein kinase $\mathrm{C}$ activation, and vascular endothelial cell growth factor expression. ${ }^{21,22)}$ It has been shown that AGEs inhibit cell growth in several cell lines. In this study, we observed that AGEs stimulated pancreatic beta-like cells to secrete insulin but that after 12-hr exposure to GFBS 
and GFBS + iron, the insulin secretion gradually decreased, with a reduction in cell viability. Thus it's clear that the effects of AGEs presumably vary according to the source of the AGEs, the type of cells used, and the culture conditions. However further studies are in progress to delineate the mechanism of AGE-mediated stimulation of insulin production by differentiated mouse ES cells.

\section{REFERENCES}

1) Nishigaki, I. (1968) A Method for determining 2thiobarbituric acid (TBA) reactive substance in fractionated blood serum. Nagoya Univ. Bull., 89, 309317.

2) Yagi, K. (1976) A simple fluorometric assay for lipoperoxide in blood plasma. Biochem. Med., 15, 212-216.

3) Hunt, J. V., Bottoms, M. A. and Mitchinson, M. J. (1993) Oxidative alterations in the experimental glycation model of diabetes mellitus are due to proteinglucose adduct oxidation. Some fundamental differences in proposed mechanisms of glucose oxidation and oxidant production. Biochem. J., 291, 529-535.

4) Ahmed, N. (2005) Advanced glycation endproductrole in pathology of complications. Diabetes Res. Clin. Pract., 67, 3-21.

5) Sato, Y., Hotta, N., Sakamoto, N., Matsuoka, S., Ohishi, N. and Yagi, K. (1979) Lipid peroxide level in plasma of diabetic patients. Biochem. Med., 21, 104-107.

6) Nishigaki, I., Hagihara, M., Tsunekawa, H., Maseki, M. and Yagi, K. (1981) Lipid peroxide levels of serum lipoprotein fractions of diabetic patients. Biochem. Med., 25, 373-378.

7) Stoppera, H., Schinzelb, R. and Sebekovac, K. (2003) Genotoxicity of advanced glycation end products in mammalian cells. Cancer Lett., 190, 151-156.

8) Sutherland, D. E., Gruessner, R. W., Dunn, D. L., Matas, A. J., Humar, A., Kandaswamy, R., Mauer, S. M., Kennedy, W. R., Goetz, F. C., Robertson, R. P., Gruessner, A. C. and Najarian, J. S. (2001) Lessons learned from more than 1,000 pancreas transplants at a single institution. Ann. Surg., 233, 463-501.

9) Luciano, V. G., Alessandra, P., Gianni, S., Anna, G., Daniela, S., Arianna, D., Fiammetta, M. and Odetti Patrizio, O. (2008) Glycated fetal calf serum affects the viability of an insulin secreting cell line in vitro. Metabolism, 57, 163-169.

10) Kume, S., Kato, S., Yamagishi, S., Inagaki, Y.,
Ueda, S., Arima, N., Okawa, T., Kojiro, M. and Nagata, K. (2005) Adanced glycation end-products attenuate human mesenchymal stem cells and prevent cognate differentiation into adipose tissue, cartilage and bone. J. Bone Miner. Res., 20, 1647-1658.

11) Nishigaki, I., Rajkapoor, B., Rajendran, P., Venugopal, R., Ekambaram, G., Sakthisekaran, D. and Nishigaki, Y. (2010) Effect of fresh apple extract on glycated protein/iron chelate-induced toxicity in human umbilical vein endothelial cells in vitro. Nat. Prod. Res., 24, 599-609.

12) Lim, M., Park, L., Shin, G., Hong, H., Kang, I. and Park, Y. (2008) Induction of apoptosis of Beta cells of the pancreas by advanced glycation end-products, important mediators of chronic complications of diabetes mellitus. Ann. N. Y. Acad. Sci., 1150, 311315.

13) Zhixin, L. I., Matthew, R., Barron, J. L. and Ming, Z. (2008) Rapid single-step separation of pluripotent mouse embryonic stem cells from mouse feeder fibroblasts. Stem Cells Dev., 17, 383-387.

14) Lowry, O. H., Rosebrougjh, N. J., Farr, A. L. and Randall, R. J. (1951) Protein measurement with the Folin Phenol Reagent. J. Biol. Chem., 193, 265-275.

15) Ganu, G. P., Jadhav, S. S. and Deshpande, A. D. (2010) Antioxidant and antihyperglycemic potential of methanolic extract of bark of MIMUSOPS ELENGIL in mice. Research Journal of Pharmaceuticals, Biological and Chemical Sciences, 1, 67-77.

16) Lumelsky, N., Blondel, O., Leng, P., Velasco, I., Ravin, R. and Mckay, R. (2001) Differentiation of embryonic stem cells to insulin-secreting structures similar to pancreatic islets. Science, 292, 13891394.

17) Hori, Y., Rulifson, I. C., Tsai, B. C., Heit, J. J., Cahov, J. D. and Kim, S. K. (2002) Growth inhibitors promote differentiation of insulinproducing tissue from embryonic stem cells. Proc. Natl. Acad. Sci. U.S.A., 99, 16105-16110.

18) Rajagopal, J., Anderson, W. J., Kume, S., Martinez, O. I. and Melton, D. A. (2003) Insulin staining of ES cell progeny from insulin uptake. Science, 299, 363.

19) Sipione, S., Eshpeter, A., Lyon, J. G., Kotbutt, G. S. and Bleackley, R. C. (2004) Insulin expressing cells from differentiated embryonic stem cells are not beta cells. Diabetologia, 47, 499-508.

20) Sensi, M., Picci, F., Pugliese, G., De Rossi, M. G., Petrucci, A. F., Cristina, A., Morano, S., Pozzessere, G., Valle, E. and Andreani, D. (1995) Role of advanced glycation end-products (AGE) in late diabetic complications. Diabetes Res. Clin. Pract., 28, 9-17. 
21) Adamis, A. P. (1998) Advanced glycation end products increase retinal vascular endothelial growth factor expression. J. Clin. Invest., 101, 1219-1224.

22) Mamputu, J. C. and Renier, G. (2002) Advanced glycation end products increase, through a protein kinase C-dependent pathway, vascular endothelial growth factor expression in retinal endothelial cells: Inhibitory effect of gliclazide. J. Diabetes Complications, 16, 284-293. 